\title{
EFFECT OF HEAT TREATMENT AND WAX IMPREGNATION ON DIMENSIONAL STABILITY OF PTEROCARPUS MACROCARPUS WOOD
}

\author{
Lin Yang ${ }^{1,2}$, Tiandi Han ${ }^{1}$, Yudong Fu ${ }^{1}$ \\ ${ }^{1}$ Nanjing Forestry University \\ China \\ ${ }^{2}$ Northeast Forestry University \\ China
}

(Received March 2020)

\begin{abstract}
In order to improve dimensional stability and control deformation, heat treatment $(\mathrm{HT})$ and wax impregnation (WI) were conducted to large size boards (LB) of Pterocarpus macrocarpus and the tangential swelling were compared in various relative humidity $(\mathrm{RH})$ conditions. The results show that the tangential swelling and shrinking of control group and treated group performed differently corresponded to various relative humidity ( $\mathrm{RH}$ ). Comparing with control group, the swelling ratio of $\mathrm{HT}$ combined WI group was much less, and followed by $180^{\circ} \mathrm{C}-3 \mathrm{~h} \mathrm{HT}$ group. The maximum swelling ratio decreased by $31 \%$ and $29 \%$ in humidity chamber and indoor conditions respectively. The swelling ratio was affected by size of samples, LB showed smaller welling ratio than small sample. Wax filled in cell cavities and presented uneven distributions after impregnation. The rate of wood hygroscopicity was reduced after HT combined WI treatment which was an effective method on improvement of wood dimensional stability.
\end{abstract}

KEYWORDS: Pterocarpus macrocarpus, heat treatment, wax impregnation, dimensional stability, modification.

\section{INTRODUCTION}

Pterocarpus macrocarpus mainly grows in Myanmar, Laos and Thailand, belonging to the butterfly-shaped flower Pterocarpus, Rosewood mahogany (Azratul et al. 2017), which is categorized as a red Suanzhimu class in China national standard- "Hongmu" (GB/T181072017). Pterocarpus macrocarpus has straight trunk, branches few and it is excellent wood tree species. The heart wood of Pterocarpus macrocarpus has important practical value due to its special 
properties such as reddish brown, texture clear and diverse which bring visual enjoyment and psychological pleasure to human (Wisittipanich et al. 2012). In addition, the mechanical property of high density and hardness of the heart wood are much better for producing high-grade rosewood furniture and works of art (Chen et al. 2018, Jiang et al. 2018, Li et al. 2018).

Recently, rosewood furniture have become more and more popular among Chinese high-end home furniture consumption due to not only its high appreciation and collection value, but also its healthy value (Jiang et al. 2016). Therefore, people paid more attention to product quality such as deformation and cracks (Liu et al. 2017, Huang et al. 2018, Zhang et al. 2019) of rosewood furniture during the process of manufacture and daily use. Wood is a natural polymer material composed of cellulose, hemicellulose and lignin (Sun et al. 2019, Sun et al. 2019) which have large amount of hydroxyl groups. Wood exhibits shrinking or swelling due to its hydroxyl groups desorbing or absorbing waters. The defects such as warping and cracking may occur when wood used in an environment with large relative humidity fluctuations. Rosewood, such as Pterocarpus macrocarpus deforms severely compared with common wood due to its high density and high extracts (Liu et al. 2017, Huang et al. 2018, Zhang et al. 2019). The defects reduce the service life and value of rosewood products.

Although wood drying improves wood dimensional stability (Liu et al. 2019a), it cannot meet further requirements of rose wood production. The dimensional stability can be improved by many ways (Beck et al. 2017, Joffre et al. 2017, Moghaddam et al. 2016, Liu et al. 2019b, Ozkan et al. 2017) which generally can be classified into chemical modification and physical modification (Altgen et al. 2016, Avamidis et al. 2011, Hosseinpourpia et al. 2017, Li et al. 2017). Although chemical modification can obtain good results of dimensional stability, it can be harmful for human health and environment (Chen et al. 2008). Heat treatment improves wood excellent water repellency performance, however, the disadvantages of darkened color and lowered mechanical strengths restrain its application (Zhang et al. 2007), especially for expensive rosewoods. The modification on wood of waxes, particularly paraffin waxes as water repellents, is a potential novel impregnation approach (Schultz et al. 2007). The wax application on wood can be divided into two categories as wax impregnation (Li et al. 2015, Scholz et al. 2010, Yang et al. 2017) and WI combined with other modification (Humar et al. 2016, Liao et al. 2016, Wang et al. 2016). Wood dimensional stability is improved and water uptake rate are reduced after wax fills the cell cavity (Kaldun et al. 2016, Sedighi et al. 2016, Xie et al. 2013). In contrast to HT, the mechanical property and natural color and texture maintains well of WI.

Although wood dimensional stability could be improved obviously by HT or WI, few researches ( $\mathrm{Li}$ et al. 2015, Qian et al. 2019) were carried out to rosewood. In addition, the effect on dimensional stability was conducted using small specimens in the laboratory. There were no previous studies on medium temperature HT combined with WI for large size boards of Pterocarpus macrocarpus. The prime object of present study was to compare the performance of wood treated by HT and subsequently WI against moisturizing in the laboratory and indoor conditions. In parallel, the distribution of the impregnation wax was observed by scanning electron microscope (SEM). These data are of vital importance for assessment of the overall performance of rosewood materials.

\section{MATERIAL AND METHODS}

\section{Material}

Some uniform and defect-free air dried Pterocarpus macrocarpus boards were used in this study which were supplied by Xian You Degoo Furniture Company, China. The initial dimension 
of the boards was $250 \mathrm{~mm}(\mathrm{~T}) \times 14 \mathrm{~mm}(\mathrm{R}) \times 2200 \mathrm{~mm}(\mathrm{~L})$. The specifications were $250 \mathrm{~mm}$ $(\mathrm{T}) \times 14 \mathrm{~mm}(\mathrm{R}) \times 420 \mathrm{~mm}(\mathrm{~L})$ specimens after sawing, and the initial moisture content $(\mathrm{MC})$ was $9 \%$. The specimens were divided into 5 groups, and each group contained 2 pieces of boards. Group 1 was used for comparison as control group, other groups were treated by heat or heat combined with WI according to the experiment design in Tab. 1. Wax was used for impregnation which has low molecular weight of $500 \mathrm{~g}$ to $800 \mathrm{~g}$ and a low melting point of $50^{\circ} \mathrm{C}$ to $60^{\circ} \mathrm{C}$.

\section{Equipment}

The equipment in this study included a heat treatment chamber (Jiangsu XingNan Wood drying equipment Co., Ltd, Nanjing, China); a constant temperature and humidity chamber (DF-408, Nanjing FuDe Instrument Co., Ltd, Nanjing, China); an electricity heat drum wind drying oven (DHG-905386-III, Shanghai Cimo Medical Instrument Co., Ltd, Shanghai, China); a scanning electron microscope (SEM, FEI Quanta 200, FEI; Holland); an Electronic balance, accuracy 0.001g (ShangHai Sincere Dedication Of Science and Technology Innovation Company).

\section{Heat treatment and wax impregnation}

In order to prevent checking during heat treatment, all specimens were dried at $60^{\circ} \mathrm{C}$ in a constant temperature and humidity chamber until the wood $\mathrm{MC}$ was $3 \%$ prior to heat treatment. The weight and dimensions of wood specimens were measured after cooling to room temperature. Then the wood specimens of group 2, 3, 4 and 5 were treated respectively in a superheated steam chamber at the designated temperature and time in Tab. 1. Group 1 of untreated wood samples served as control for comparison purposes. After cooling, group 3 were fully immersed into liquefied wax in a steel tank at $60^{\circ} \mathrm{C}$ and were treated for $264 \mathrm{~h}$ (11 days). After impregnation, the specimens were kept at a constant temperature of $30^{\circ} \mathrm{C}$ for $1 \mathrm{~h}$ after wiping the residual impregnation wax, and then the weight and dimensions were measured.

Tab. 1: Experimental design of the treatment processes.

\begin{tabular}{|c|c|c|c|}
\hline Group & Treatment & Temperature $\left({ }^{\circ} \mathrm{C}\right)$ & Time $(\mathrm{h})$ \\
\hline 1 & - & - & - \\
\hline 2 & Heat & 130 & 6 \\
\hline 3 & Heat & 130 & 6 \\
\hline 4 & Heat & 150 & 3 \\
\hline 5 & Heat & 180 & 3 \\
\hline 3 & Heat + Wax & 60 & 264 \\
\hline
\end{tabular}

\section{Estimation of dimensional stability}

The degree of dimensional stability was determined by estimating the tangential swelling ratio $(\mathrm{S})$ using hygroscopicity testing. Despite the comprehensive literature on the dimensional stability of small size HT wood, limited information is available concerning the behavior of large size HT hardwoods. Therefore the dimensional stability of small size samples and large size boards (LB) were compared in this study. Seven small samples of size $20 \mathrm{~mm}(\mathrm{~T}) \times 14 \mathrm{~mm}$ $(\mathrm{R}) \times 20(\mathrm{~L}) \mathrm{mm}$ were prepared for each group. They were produced from the middle part of a slat which was sawn from the second board in each group. Large size boards, $415 \mathrm{~mm}(\mathrm{~T}) \times$ $14 \mathrm{~mm}(\mathrm{R}) \times 420 \mathrm{~mm}(\mathrm{~L})$, were glue jointed using the first board and the left parts of the second board. Finally, small samples together with large size boards were oven-dried at $103 \pm 2{ }^{\circ} \mathrm{C}$ until a constant weight and dimensions were obtained prior to dimensional stability test. 
Moisture performance of wood material may be affected by test methods and duration (Davor et al. 2020). Therefore, for LB, the dimensional stability tests of control group, HT groups and HT combined WI group were conducted in a humidity chamber and indoor environment. For small samples, only indoor tests were conducted. To imitate the wet and dry end-use conditions, $\mathrm{LB}$ were conditioned for several weeks first at $40^{\circ} \mathrm{C}$ and $90 \%$ and then at $40^{\circ} \mathrm{C}$ and $35 \%$. The weights and tangential dimensions at three locations were measured once every 2 days during the chamber testing. Then, LB together with small samples underwent dimensional stability testing at indoor environment of $10-30^{\circ} \mathrm{C}$ and $45 \%-75 \% \mathrm{RH}$, measurements of weights and tangential dimensions were conducted once every 1-2 months. The tangential swelling ratio (S) was determined by the following equation:

$$
S=100 \times\left(L_{1}-L_{0}\right) / L_{0}
$$

where: $\quad L_{1}$ is tangential dimension of sample at measurement,

$L_{0}$ is tangential dimension of the oven-dried sample.

\section{Distribution of the wax in wood}

In order to investigate the extent of WI and the internal wax distribution, three pieces of wood from control, $180^{\circ} \mathrm{C}-3 \mathrm{~h} \mathrm{HT}$, and the $\mathrm{WI}$ groups were randomly selected. The cross sections were observed by scanning electron microscopy (SEM).

\section{RESULTS AND DISCUSSION}

\section{Dimensional change characteristics of large size boards in the humidity chamber}

Fig. 1 is the swelling ratio curves of LB during absorption and desorption process in humidity chamber and indoor environment. In order to compare the dimensional changes of modified wood, the detailed swelling and shrinking ratio curves are presented in Fig. 2 and Fig. 3, resp. Fig. 2 shows swelling characteristics during absorption process (0-32 days) in a high $\mathrm{RH}$ of $90 \%$ and shrinking characteristics during desorption process (32-54 days) in a low $\mathrm{RH}$ of $35 \%$. Fig. 3 presents the swelling and shrinking characteristics (54-473 days) of indoor environment. It was observed that the ratio of swelling and shrinking in humidity chamber differed from that of indoors, which may be mainly attributed to RH in both conditions. Wood swell and shrink proportionally with the magnitude of the change in their moisture content (Cai et al. 2019). High swelling ratio is mainly attributed to wood cell wall absorbed more water vapor in higher RH condition.

As seen in Fig. 2, the swelling ratio of LB differed from modified conditions during the absorption process (0-32 days) which underwent a rapid increasing (0-10 days) and a slow increasing (10-32 days) phases. Shrinkage ratio of LB presented almost same during the initial 3 days, and it differed obviously after that until the 10th day. The shrinkage ratio during rapid increasing phase of modified groups was less than control group and the minimum was the condition of HT combined WI. In the following slow increasing phase (10-32 days), the difference of swelling ratio became clearly, i.e., the maximum were about $2.44 \%$ for control group, following was $\mathrm{HT}$ group of $130^{\circ} \mathrm{C}-6 \mathrm{~h}$ and $150^{\circ} \mathrm{C}-3 \mathrm{~h}$ which were almost the same, $180^{\circ} \mathrm{C}-3 \mathrm{~h}$ and the minimum of HT combined WI was about $1.68 \%$. Compared with control group, swelling ratio of $180^{\circ} \mathrm{C}-3 \mathrm{~h} \mathrm{HT}$ and $\mathrm{HT}$ combined WI were reduced by $22 \%$ and $31 \%$ respectively during absorption process. These indicated that dimensional stability was improved significantly at these 
two conditions. Increase in dimensional stability of HT wood is mainly attributed to decrease in hygroscopicity due to degradation of some hemicelluloses and an increase in condensed lignin bonds (Esteves and Pereira 2009). While the primary cause leading great dimensional stability enhancement for wood of HT combined WI may be wood empty space were filled with wax which functioned as an excellent bulking medium ( $\mathrm{Li}$ et al. 2015).

In Fig. 2, it was observed that the swelling ratio of $\mathrm{LB}$ also presented rapid decreasing and slow decreasing phase during the desorption process (32-54 days). The swelling ratio decreased rapid during the initial period (32-38 days) and then decreasing became slowly after that. In this phase, the swelling ratio of $\mathrm{LB}$ were also affected by modified conditions, i.e., the lowest was $\mathrm{HT}$ combined WI group, followed by $180^{\circ} \mathrm{C}-3 \mathrm{~h} \mathrm{HT}$, and then $130-6 \mathrm{~h} \mathrm{HT}$ and $150^{\circ} \mathrm{C}-3 \mathrm{~h} \mathrm{HT}$ which were almost the same, and the highest was the control group. However, during the slow decreasing phase, swelling ratio of HT combined WI group was much less than others groups. There was little difference between control group and only HT groups. This indicated that the HT combined WI could significantly reduce wood hygroscopicity and improve its dimensional stability.

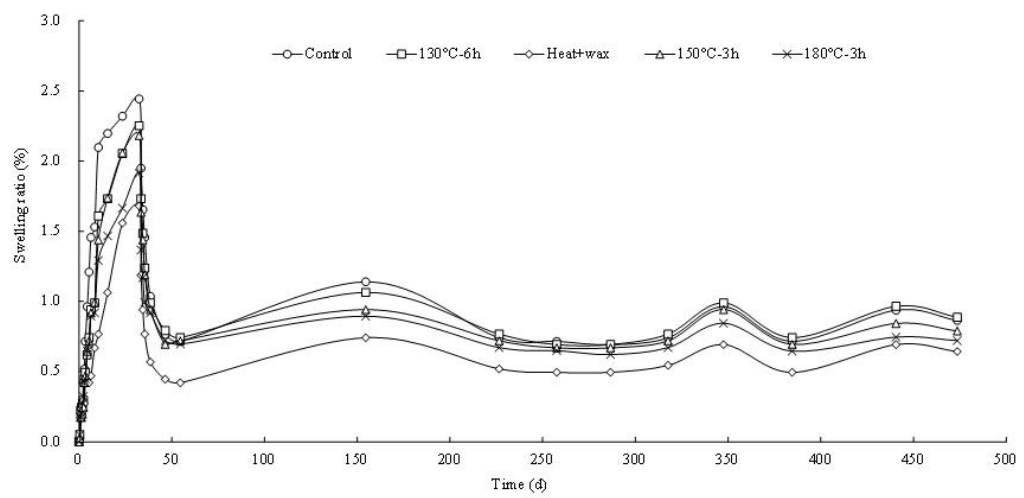

Fig. 1: Curves of tangential swelling ratio of $L B$ in humidity chamber and in indoor conditions.

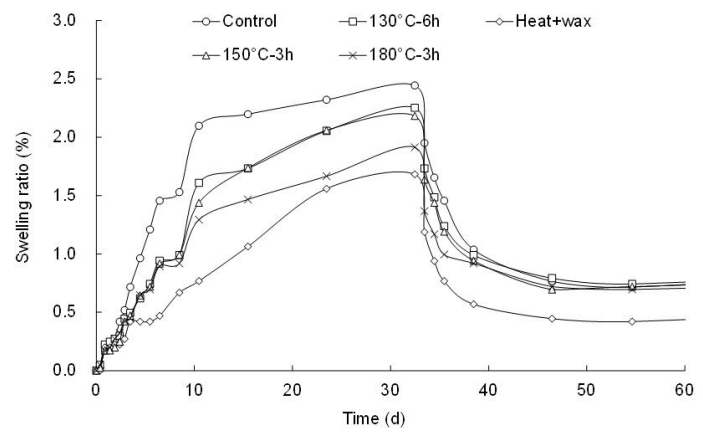

Fig. 2: Curves of tangential swelling ratio of $L B$ in humidity chamber.

\section{Dimensional change characteristics of large size boards in indoor condition}

Fig. 3 is the swelling ratio curves of LB in indoor environment which can show the real swelling and shrinking performance of wide boards in furniture or wooden products. Tab. 2 
is the swelling ratios during the test. It was observed that the changes of all groups presented similar tendency which swell or shrink with seasonal climatic conditions of temperature and RH changing. The change of wood dimension is mainly influenced by the temperature and $\mathrm{RH}$ of the environment, among which the humidity plays an important role. LB swelled in higher RH season and shrunk in lower RH season. It can be seen in Fig. 3, the swelling ratios were great in December, July and October due to the high RH in these months. In contrast, dimensions changes of LB were small in March, April, May and June, because the RH varied few in these months. As seen in Fig. 3 and Tab. 2, the swelling ratios of LB were affected by treated conditions. The lowest was the HT combined WI group, which were much less than other HT and control groups and following were $180^{\circ} \mathrm{C}-3 \mathrm{~h} \mathrm{HT}, 150^{\circ} \mathrm{C}-3 \mathrm{~h} \mathrm{HT}$ groups. The maximum swelling ratio of HT combined WI group and $180^{\circ} \mathrm{C}-3 \mathrm{~h} \mathrm{HT}$ group at indoor condition decreased by $29 \%$ and $13 \%$ respectively compared with control group. The swelling ratio of $130^{\circ} \mathrm{C}-6 \mathrm{~h}$ HT group and control group were almost same, this indicated that there was no effect on improvement of dimensional stability at this temperature condition. However, the dimensional stability of LB at $130^{\circ} \mathrm{C}-6 \mathrm{~h}$ HT was obviously improved after wax impregnation. This showed that WI could significantly improve wood dimensional stability. The results coincide with the report in previous study ( $\mathrm{Li}$ et al. 2015). It was also observed in Tab. 2 that the range of swelling ratio of HT combined WI group was $0.25 \%$, which resulted in the maximum dimension variation only within $1 \mathrm{~mm}$ for $415 \mathrm{~mm}$ wide board in a year. This dimension variation fully meets the requirement of manufacture and can prevent furniture components cracking and deformation.

Tab. 2: Tangential swelling ratio of LB in indoor conditions (\%).

\begin{tabular}{|l|c|c|c|c|c|c|c|c|c|c|c|c|c|}
\hline \multicolumn{1}{|c|}{ Group } & Dec & Mar & Apr & May & Jun & Jul & Aug & Oct & Nov & Mean & Max & Min & Range \\
\hline Control & 1.14 & 0.74 & 0.72 & 0.69 & 0.74 & 0.96 & 0.72 & 0.94 & 0.86 & 0.83 & 1.14 & 0.69 & 0.45 \\
\hline $130^{\circ} \mathrm{C}-6 \mathrm{~h}$ & 1.06 & 0.77 & 0.69 & 0.69 & 0.77 & 0.99 & 0.74 & 0.97 & 0.89 & 0.84 & 1.06 & 0.69 & 0.37 \\
\hline $150^{\circ} \mathrm{C}-3 \mathrm{~h}$ & 0.94 & 0.72 & 0.67 & 0.67 & 0.72 & 0.94 & 0.69 & 0.84 & 0.79 & 0.78 & 0.94 & 0.67 & 0.27 \\
\hline $180^{\circ} \mathrm{C}-3 \mathrm{~h}$ & 0.89 & 0.67 & 0.65 & 0.62 & 0.67 & 0.85 & 0.65 & 0.75 & 0.72 & 0.72 & 0.89 & 0.62 & 0.27 \\
\hline Heat + wax & 0.74 & 0.52 & 0.49 & 0.49 & 0.54 & 0.69 & 0.49 & 0.69 & 0.64 & 0.59 & 0.74 & 0.49 & 0.25 \\
\hline
\end{tabular}



Fig. 3: Curves of tangential swelling ratio of $L B$ in indoor conditions. 


\section{Swelling comparison of large size boards and small samples}

Because the swelling ratio of LB in December was the biggest in a year, it is compared with small samples in Fig. 4.

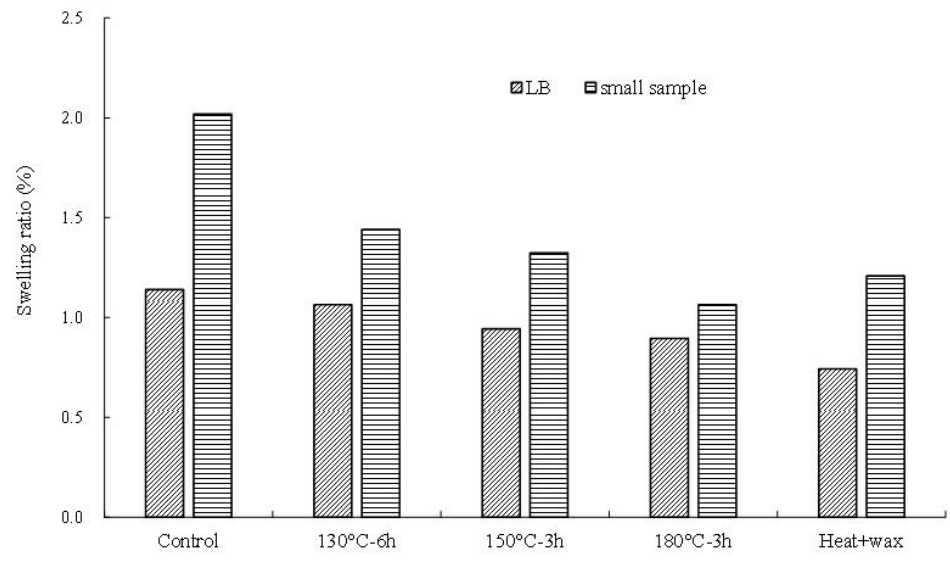

Fig. 4: Comparison of tangential swelling ratio of $L B$ and small samples in December.

The swelling ratio of small samples was compared with the value in previous study of wax impregnation to Aniba rosaeodora ( $\mathrm{Li}$ et al. 2015), they were almost the same. It was observed that swelling ratio of all groups of LB were smaller than that of small samples, this indicating the swelling ratio was affected by dimensions of material. It may be attributed to the anisotropic properties of wood swelling, i.e., wood swells greatest in tangential direction, followed by radial direction which is about half the tangential direction and the lowest in fiber direction. Growth rings of small samples are almost parallel to tangential direction, this leading to biggest swelling. However, LB were glued jointed with pieces of boards, the growth rings presented multiple angles to tangential direction which restrict overall swell, thus swelling in tangential was reduced for LB. In production process, swelling amount of wooded product components was normally calculated based the swelling ratio of small samples. However, the factually amount of swelling are smaller than that calculated according to the results above and special attentions should be paid to determination of components swellings. In addition, the swelling ratios of treated wood were reduced for both LB, while the difference of small samples was obvious. The possible reason is the restriction to swelling of anisotropic properties of LB.

\section{Wax distribution in wood}

Microstructures of the HT wood and the distribution of the impregnated wax within the wood were observed by SEM. Comparing with control group, although HT at 180-3h, the cells of wood fiber and axial parenchyma could be clearly seen, and cell deformation and obvious attachments inside the lumens were invisible. Fig. $5 \mathrm{c}$ shows the cross section of specimen tested with HT combined WI. It was observed clearly that wax mostly presented a massive distribution and distinctly shaped droplets on the surface which were marked with arrows added points, cells were covered partly with wax, the overall distribution were not even. Similar distribution of wax was also reported by Qian et al. (2019). This figure indicated that cell cavities were filled with wax after treatment, which leading to the rate of hygroscopicity and water absorption of wood was reduced (Papadopoulos and Pougioula 2010) and the improvement of wood dimensional stability. 

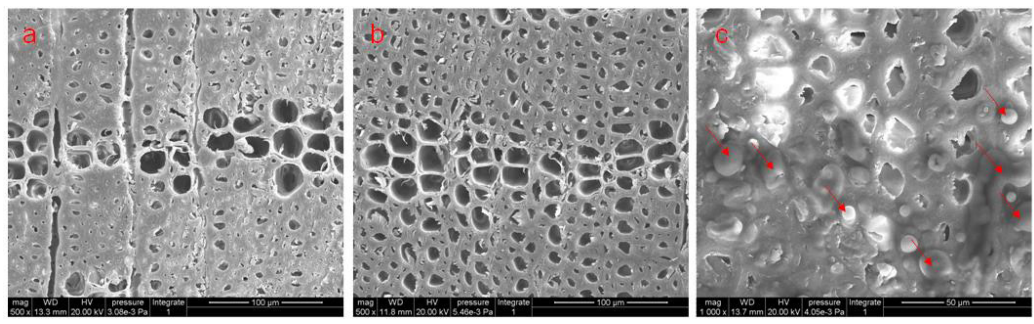

Fig. 5: The SEM of the control group and treated groups. (a) Control, (b) $180^{\circ} \mathrm{C}-3 \mathrm{~h}$, (c) Heat + wax.

\section{CONCLUSIONS}

In order to improve the dimensional stability of Pterocarpus macrocarpus wood, large size boards were treated by heat and heat combined wax impregnation and the tangential swelling ratios of treated wood were compared under various $\mathrm{RH}$ conditions. The primary results are summarized as follows.

The tangential swelling and shrinking of LB for both control group and treated group underwent a rapid followed by slow increasing and a rapid followed by slow decreasing process in humidity chamber absorption condition of $40^{\circ} \mathrm{C}-90 \% \mathrm{RH}$ and desorption condition of $40^{\circ} \mathrm{C}-35 \%$ $\mathrm{RH}$ respectively. Compared with control group, tangential swelling ratio of HT combined WI was the smallest, and the following was of $180^{\circ} \mathrm{C}-3 \mathrm{~h}$ HT group, the maximum reducing was $31 \%$ and $22 \%$ respectively during this process. The performance of swelling of treated groups were obviously different from control group during absorption condition, while only HT combined WI group was clearly different from others including control group. In contrast to humidity chamber condition, tangential swelling and shrinking in indoor condition became slow and presented small fluctuations in a year. The swelling ratio of HT combined WI group was the lowest which was obviously different from other HT groups. The maximum swelling ratio of HT combined WI group and $180^{\circ} \mathrm{C}-3 \mathrm{~h}$ HT group at indoor condition decreased by $29 \%$ and $13 \%$ respectively compared with control group. The swelling ratio was affected by size of samples, LB showed smaller welling ratio than small sample. Wax filled in cell lumens, showing uneven distributions, which resulted in decreasing in hygroscopicity rate of wood. HT combined WI was an effective method on improvement of dimensional stability wood.

\section{ACKNOWLEDGEMENTS}

This study was financially supported by the National Natural Science Foundation of China (Grant No. 31870545 and 31570558) and Key Laboratory of Bio-based Material Science \& Technology (Northeast Forestry University), Ministry of Education (SWZ-MS201903).

\section{REFFERENCES}

1. Altgen, M., Hofmann, T., Militz, H., 2016: Wood moisture content during the thermal modification process affects the improvement in hygroscopicity of Scots pine sapwood. Wood Science and Technology 50(6): 1181-1195. 
2. Avamidis, G., Scholz, G., Nothnick, E., Militz, E., Viol, W., Wolkenhauer, A., 2011: Improved bondability of wax-treated wood following plasma treatment. Wood Science and Technology 45(2): 359-368.

3. Azratul, A., Akbar, J., Kamaruzzaman, B., Sheikh, H., Jalal, K., Noor Faizul, H.N., 2017: Biomonitoring selected heavy metal concentration in Nerita sp. collected from Tanjung Lumpur Mangrove forest. Environment \& Ecosystem Science 1(1): 4-7.

4. Beck, G., Thybring, E.E., Thygesen, L.G., Hill, C., 2017: Characterization of moisture in acetylated and propionylated Radiata pine using low-field nuclear magnetic resonance (LFNMR) relaxometry. Holzforschung 72: 225-233.

5. Cai, C.Y., Heräjärvi, H., Haapalaa, A., 2019: Effects of environmental conditions on physical and mechanical properties of thermally modified wood. Canadian Journal of Forest Research 49: 1434-1440.

6. Chen, J.T., Ni, C.Y., Zhang, Z.F., Wang, L.S., Liu, Z.L., Peng, W.X., 2018: GC-MS explores health care components in the extract of Pterocarpus macarocarpus Kurz. Saudi Journal of Biological Sciences 25(6): 1196-1201.

7. Chen, G.D., Fu, Y.L., Zheng, W.J., Huang, Z.Y., Wei, Q.J., Huang, B., Wei, Z.C., Liu, Z., 2008: Research of China wood's properties improved by silicon dioxide. Guangxi Sciences 15(4): 411-444.

8. Kržišnik, D., Lesar, B., Thaler, N., Planinšič, J., Humar, M., 2020: A Study on the moisture performance of wood determined in laboratory and field trials. European Journal of Wood and Wood Products 78: 219-235.

9. Esteves, B.M., Pereira, H.M., 2009: Wood modification by heat treatment: a review. BioResources 4(1): 370-404.

10. Hosseinpourpia, R., Adamopoulos, S., Holstein, N., Mai, C., 2017: Dynamic vapour sorption and water-related properties of thermally modified Scots pine (Pinus sylvestris L.) wood pretreated with proton acid. Polymer Degradation and Stability 138: 161-168.

11. Huang, X.Y., Chen, Z.Y., Huang, M.H., Guo, J., Hu, C.B., Ma, X.N., Xu, D.J., 2018: The status quo and development trend of mahogany furniture industry. Furniture \& Interior Design 7: 70-71.

12. Humar, M., Kržišnik, D., Lesar, B., Thaler, N., Ugovšek, A., Zupančič, K., Žlahtič, M., 2016: Thermal modification of wax-impregnated wood to enhance its physical, mechanical, and biological properties. Holzforschung 71(1): 57-64.

13. Jiang, T., Li, K.F., Liu, H.H., Yang, L., 2018: Extraction of biomedical compounds from the wood of Pterocarpus macarocarpus Kurz heartwood. Pakistan Journal of Pharmaceutical Sciences 31(3): 913-918.

14. Jiang, T., Li, K.F., Liu, H.H., Yang, L., 2016: The effects of drying methods on extract of Dalbergia cochinchinensis pierre. European Journal of Wood and Wood Products 74(5): 663-669.

15. Joffre, T., Segerholm, K., Persson, C., Bardage, S.L., Hendriks, C.L.L., Isaksson, P., 2017: Characterization of interfacial stress transfer ability in acetylation-treated wood fibre composites using x-ray microtomography. Industrial Crops and Products 95: 43-49.

16. Kaldun, C., Dahle, S., Maus-Friedrichs, W., Namyslo, J.C., Kaufmann, D.E., 2016: Chemical improvement of surfaces. Part 4: Significantly enhanced hydrophobicity of wood by covalent modification with p-silyl-functionalized benzoates. Holzforschung 70(5): 411-419.

17. Li, M.M., Xie, W.B., Wang, X.W., Cao, Y., Wang, Z., 2018: Parameters optimization for ultrahigh-pressure pure water and abrasive water jet of Pterocarpus macarocarpus Kurz processing. Wood Research 63(5): 783-794. 
18. Li, T., Cheng, D.L., Avramidis, S., Wålinder, M.E.P., Zhou, D.G., 2017: Response of hygroscopicity to heat treatment and its relation to durability of thermally modified wood. Construction and Building Materials 144: 671-676.

19. Li, X., Huang, Q., Wu, Y., Li, X., Chen, Z., 2015: Impregnation with microcrystalline wax to improve rosewood dimensional stability and surface hardness. BioResources 10(3): 5994-6000.

20. Liao, Y., Zhong, H., Erni, M., 2016: Stress relaxation of paraffin wax emulsion/ copper azole compound system treated wood. Agricultural Science \& Technology 17(5): 1243-1248.

21. Liu, H.H., Yang, L., Wu, Z.H., Cai, Y.C., Li, X.C., 2017: Study on radio-frequency vacuum drying of three rosewood thin boards. Journal of Forestry Engineering 2: 15-19.

22. Liu, H.H., Zhang, J.W., Jiang, W.J., Cai, Y.C., 2019a: Characteristics of commercial scale radio frequency/ vacuum (RF/V) drying for hardwood lumber. BioResources 14(3): 6923-6935.

23. Liu, M.L., Li, C.F., Liu, Y.L., 2019b: Phsysical and mechanical properties of modified poplar wood by heat and impregnation of sodium silicate solution. Wood Research 64(1): 145-154.

24. Moghaddam, M., Wålinder, M.E.P., Claesson, P.M., Swerin, A., 2016: Wettability and swelling of acetylated and furfurylated wood analyzed by multicycle wilhelmy plate method. Holzforschung 70(1): 69-77.

25. Ozkan, O.E., Temiz, A., Vurdu, H., 2017: Effects of heat treatment on Turkish fir wood properties. Wood Research 62(5): 783-794.

26. Papadopoulos, A.N., Pougioula, G., 2010: Mechanical behaviour of pine wood chemically modified with a homologous series of linear chain carboxylic acid anhydrides. BioResources Technology 101(15): 6147-6150.

27. Qian, J., Li, J.P., Wang, Z.Y., Qu, L.J., Ding, Y., Yi, S.L., He, Z.B., 2019: Effect of wax and dimethyl silicone oil mixed impregnation on dimensional stability of two hardwoods. Wood Research 64(1): 165-176.

28. Scholz, G., Militz, H., Gascon-Garrido, P., Ibiza-Palacios, M., Oliver-Villanueva, J., Peters, B., Fitzgerald, C., 2010: Improved termite resistance of wood by wax impregnation. International Biodeterioration \& Biodegradation 64(8): 688-693.

29. Schultz, T.P., Darrel, D.N., Ingram, L.L., 2007: Laboratory and outdoor water repellency and dimensional stability of Southern pine sapwood treated with waterborne water repellent made from resin acids. Holzforschung 61(3): 317-322.

30. Sedighi Moghaddam, M., Heydari, G., Tuominen M., Fielden, M., Haapanen, J., Mäkelä, J.M., Wålinder, M.E.P., Claesson, P.M., Swerin, A., 2016: Hydrophobisation of wood surfaces by combining liquid flame spray (LFS) and plasma treatment: dynamic wetting properties. Holzforschung 70: 527-537.

31. Sun, S., Zhao, Z., Shen, J., 2019: Effects of the manufacturing conditions on the VOCs emissions of particleboard. BioResources 15(1): 1074-1084.

32. Sun, S., Zhao, Z., Umemura, K., 2019: Further exploration of sucrose-citric acid adhesive: synthesis and application on plywood. Polymers 11(11): 1875.

33. Wang, J., Zhong, H., Ma, E., Cao, J., 2016: Properties of wood treated with compound systems of paraffin wax emulsion and copper azole. European Journal of Wood and Wood Products 76: 315-323.

34. Wisittipanich, S., Khadee, C., Jintana, P., 2012: Shoot production of plus tree branch log and it's cutting test of Tectona grandis Linn and Pterocarpus macrocarpus Kurz. Kasetsart University Conference, 2580, pp.396-405, ref.6. 
35. Xie, Y., Fu, Q. Wang, Q., 2013: Effects of chemical modification on the mechanical properties of wood. European Journal of Wood and Wood Products 71: 401-416.

36. Yang, X., Tingzu, X., Zhang, L., Gang, Y., Lan, M., Pang, K., 2017: Impregnating technology and physical mechanics properties of wax impregnated wood for outdoor use. Journal of Forest \& Environment 37(4): 496-501.

37. Zhang Y., Jin J., Wang S., 2007: Effects of resin and wax on the water uptake behavior of wood strands. Wood and Fiber Science 39(2): 271-278.

38. Zhang, Y., Xu, K.W., Lu, Y.H., Fang, J.J., 2019: Effect of paraffin oil bath treatment on Hongmu color. China Wood-based Panels 11: 10-14.

*Lin YANG

${ }^{1}$ Nanjing Forestry University

College of Furnishing and Industrial Design

NANJING 210037

China

${ }^{2}$ Northeast Forestry University

Ministry of Education

Key Laboratory of Bio-Based Material Science \& Technology

HARBIN I5OO4O

China

*Corresponding author: forest-yang@163.com 
